BLS 35, No 1 2009. DOI: http://dx.doi.org/10.3765/bls.v35i1.3614

(published by the Berkeley Linguistics Society and the Linguistic Society of America)

\title{
Interpretative Effects of Multiple Determiners in Greek
}

\author{
MARIKA LEKAKOU and KRISZTA SZENDRÖI \\ Meertens Institute, Amsterdam and University College London
}

\section{Introduction}

The topic of this paper is the so-called polydefinite construction in Modern Greek (henceforth Greek), i.e. cases of adjectival modification in which the adjective is accompanied by its own determiner.
a. $\mathrm{i}$ asimenia $\mathrm{i}$ pena the silver the pen
b. $\mathrm{i}$ pena $\mathrm{i}$ asimenia the pen the silver

A number of syntactic and semantic/pragmatic differences exist between polydefinites and 'regular' adjectival modification (or monadic definites, a term which, like the term polydefinite, is due to Kolliakou (2004)). First, the ordering freedom displayed by polydefinites is not attested in the case of monadic definites; the latter only allow the adjective in prenominal position:
a. i asimenia pena the silver pen
b. ${ }^{*} \mathrm{i}$ pena asimenia the pen silver

When more than one adjective is present, all possible word orders are grammatical in the polydefinite:
a. $\mathrm{i}$ pena $\mathrm{i}$ asimenia $\mathrm{i}$ kenurja the pen the silver the new
b. i pena i kenurja $i$ asimenia
c. i asimenia i pena i kenurja
d. i asimenia i kenurja i pena
e. i kenurja i asimenia i pena
f. i kenurja i pena i asimenia

Second, as Kolliakou (op. cit.) observed, adjectives in the polydefinite construction are obligatorily interpreted restrictively (which, as we discuss in detail in section 1.2, has repercussions for the set of admissible adjectives). Since as a 


\section{Marika Lekakou and Kriszta Szendrői}

matter of world knowledge all cobras are poisonous (there are no non-poisonous cobras), the adjective 'poisonous' when applied to cobras cannot receive a restrictive interpretation and hence is not licit in the polydefinite construction:

$$
\begin{aligned}
& i \text { dilitiriodis }(\# i) \text { kobres } \\
& \text { the poisonous the cobras }
\end{aligned}
$$

Finally, there is no equivalent of the polydefinite construction with the indefinite determiner (Alexiadou and Wilder 1998; but cf. Stavrou 2009):

$$
\begin{gathered}
\text { a. *mia pena mia asimenia } \\
\text { a pen a silver } \\
\text { b. *mia asimenia mia pena } \\
\text { a silver a pen }
\end{gathered}
$$

The purpose of this paper is twofold. One is to show that a common conception of polydefinites as involving predication is not warranted. In particular, the set of admissible adjectives and the restrictive interpretation thereof can be derived without further ado on the basis of an approach to polydefinites that posits noun ellipsis (Panagiotidis 2005, Lekakou and Szendröi 2007, 2009). The second aim is to derive the actual occurrence of multiple determiners. We point out that the very hallmark of the polydefinite construction (also known as determiner spreading) is dealt with in most existing analyses in a stipulative fashion, and that our own alternative (Lekakou and Szendröi, op.cit.) fares better. Moreover, we provide an explicit, albeit provisional answer to a question that has thus far been left unaddressed: What are the implications of determiner spreading for the semantics of definiteness in Greek?

In section 1 we summarize the key properties of our previous work on polydefinites: Section 1.1 discusses close apposition, and section 1.2 applies the proposal to polydefinites with particular reference to deriving the interpretation and distribution of adjectives in the construction. In section 2 we deal with the multiple occurrence and interpretation of the definite determiner.

\section{Polydefinites As an Instance of Close Apposition}

\subsection{Close Apposition: The Syntax and Semantics of R-role Identification}

In Lekakou and Szendröi $(2007,2009)$ we have provided an account of polydefinites as an instance of close apposition (henceforth CA), as in (6) and (7). ${ }^{1}$ Specifically, we have argued that both CA and polydefinites are DPs whose subparts are DPs themselves (the only difference is that the latter but not the former involve noun ellipsis).

\footnotetext{
${ }^{1}$ Close apposition is distinguished from loose apposition on the basis of prosodic, syntactic and semantic properties. We discuss these differences in Lekakou and Szendröi (2007).
} 
(6)
a. o aetos to puli
the eagle the bird
b. to puli o aetos
the bird the eagle

(7) a. Burns the poet

b. the poet Burns

CA shares the core properties displayed by polydefinites that we identified above. First, as shown in (6) and (7), the order within the larger constituent is free. Second, CA is only possible with definite DPs (Stavrou 1995):
a. *enas aetos (ena) puli
an eagle a bird
b. *ena puli (enas) aetos
a bird an eagle

Thirdly, one of the sub-parts of CA is obligatorily interpreted restrictively with respect to the other sub-part. This is illustrated in the following example from Potts (2005) (see also Kolliakou 2004):

(9) Armstrong the Texan is a cyclist. Armstrong the Ohioan is an astronaut.

In (9), the Texan and the Ohioan restrict the denotation of Armstrong. Put differently, the use of Armstrong is not enough to establish who the referent of the DP is. It is through 'co-operation' between both subparts that reference assignment is made possible (even though both subparts would independently be able to refer).

Capitalizing on the fact just noted, namely that in CA, both subparts jointly contribute to reference, we have proposed that CA (and polydefinites, as a case thereof) involves a process of identification of R(eferential)-roles. Following Williams (1981, 1989), the R-role is the external theta role of nominal elements, and it is what enables nominal elements to act as referential arguments. In CA, we argue, two independent R-roles become identified (cf. the identification of thematic roles in adjectival modification, as discussed by Higginbotham (1985)). This identification takes place under sisterhood, i.e. within a multi-headed syntactic structure (see Baker and Stewart 1999 for the conceptual considerations pertaining to such structures, and for an application to serial verb constructions): ${ }^{2}$

\footnotetext{
${ }^{2}$ As is obvious, the ordering freedom of CA is consistent with the symmetric syntactic structure we propose. Additionally, since only nominal elements are endowed with R-roles, we capture the fact that CA is only possible with nominals (Huddleston and Pullum 2002).
} 


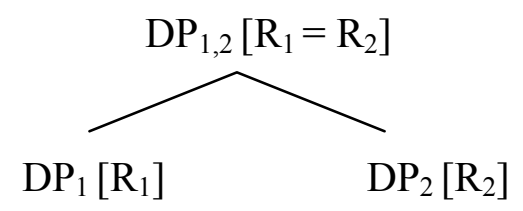

Evidence in favour of the symmetric structure in CA comes from agreement facts given in (11), where the adjective in predicative position can agree for gender with either subpart of the CA in subject position. Since agreement privileges no particular subpart of CA, neither can be thought of as its head:
a. o aetos to puli ine megaloprepos/megaloprepo. the.M eagle.M the.N bird.N is majestic.M/majestic.N
b. to puli o aetos ine megaloprepos/megaloprepo. the.N bird.N the.M eagle.M is majestic.M/majestic.N

In terms of the semantics, R-role identification is interpreted as set intersection (see Higginbotham (1985), and also the operation of predicate modification of Heim and Kratzer (1998)): The larger DP refers to an entity that belongs to both sets designated by the smaller DP-subparts. We assume that applicability of this operation is subject to a ban against vacuous application. Given this assumption, it follows that nominals whose R-roles are independently identical cannot form parts of CA. This belies the ungrammaticality of (12), noted by Stavrou (1995:225), and of (13) (the Bard conventionally refers to Shakespeare):

$$
\begin{array}{ll}
*_{i} \text { sikaminja } & \text { i murja } \\
\text { the blueberry-tree } & \text { DIALECTAL } \\
\text { the bluberry-tree } & \text { STANDARD }
\end{array}
$$

\section{*Shakespeare the Bard}

The ban on vacuous application of R-role identification does not only rule out independently identical R-roles from becoming identified; it also forces a restrictive interpretation. Let us see why. 'Regular' set intersection allows for a situation where one set is completely contained in the other, i.e. a set-subset situation. For instance, the set of cobras is a subset of the set of poisonous entities: Being a member of the set of cobras entails being a member of the set of poisonous entities. To wit, membership in the smaller set automatically gives you membership in the bigger set. Under such circumstances, R-role identification is disallowed, since its application would yield a result already in effect.

The implication of our treatment of CA is that the two subparts, despite being formally DPs, denote predicates: They have to be of type $<$ e,t $>$ and not of type $<\mathrm{e}>$ (or $<<\mathrm{e}, \mathrm{t}>, \mathrm{t}>$ ). We take this up in section 2 where we become more explicit about the semantics of definiteness in Greek. 


\section{Multiple Determiners in Greek}

\subsection{Polydefinites: The Import of Noun Ellipsis}

Going back to polydefinites, we propose that the latter are identical to CA and only differ in that one of the DP-subparts, namely the one containing the adjective, contains noun ellipsis. The structure we propose is given in (14):

$$
\begin{aligned}
& \text { a. }[\mathrm{DP}[\mathrm{DP} \text { to spiti] }[\mathrm{DP} \text { to megalo } \varnothing]] \\
& \text { the house the big } \\
& \text { b. }[\mathrm{DP}[\mathrm{DP} \text { to megalo } \varnothing[\mathrm{DP} \text { to spiti] }] \\
& \text { the big the house }
\end{aligned}
$$

Positing noun ellipsis brings about a number of welcome results. Besides allowing us to maintain a one-to-one correspondence between number of overt D's and number of constituent DPs, it enables us to explain why in polydefinites it is necessarily the 'adjectival' DP that is interpreted restrictively with respect to the 'nominal' DP, even though it would in principle be possible for things to be the other way around. A well-known property of ellipsis is that non-elided material must be informative, or disanaphoric (cf. Williams 1997, and Giannakidou and Stavrou 1999 specifically for Greek). One way to satisfy this requirement on ellipsis is to receive a restrictive interpretation. In other words, it seems to be generally the case that noun ellipsis forces a restrictive interpretation on nonelided (adjectival) material. This is, we argue, also evident in the case in polydefinites (see Kolliakou 2004 for extensive discussion). ${ }^{3}$

Given this general fact about noun ellipsis, we expect the distribution of adjectives in polydefinites to pattern accordingly. To wit, we expect all and only the set of adjectives that can be interpreted restrictively/appear in noun ellipsis contexts to be licit in polydefinites. As we show below, this is indeed the case.

Alexiadou and Wilder (1998) and Alexiadou (2001) note that relational adjectives like ekdotikos 'publishing' (as in ekdotikos ikos 'publishing house'), and adjectives in proper names like Vorios 'North' in o Vorios Polos 'the North Pole' are unacceptable in polydefinites. They argue that this is because such adjectives form a compound with the noun (see also Ralli and Stavrou 1998). This suffices to rule them out in polydefinites: Compound-like A-N collocations are not amenable to taking part in constructions that would require their adjectival part (or the nominal one) to act as an independent syntactic head. As (15) and (16) show, such adjectives are also impossible in noun ellipsis contexts. ${ }^{4}$

\footnotetext{
${ }^{3}$ This property of polydefinites has been related by essentially every existing proposal in the literature to a DP-internal FocusPhrase. In our view, this is neither necessary (since ellipsis suffices to derive the alleged focus-effects), nor sufficient, as there are discrepancies between polydefinites and focally stressed adjectives (in polydefinites). See Lekakou and Szendrői (2007, 2009) for elaboration of this point, and for the empirical arguments against the view that a Focus Phrase is at play.

${ }^{4}$ On the other hand, we do expect these collocations to occur in a polydefinite as the (lexically realized) nominal subpart, and this is indeed true. Note that examples such as (ia) cannot be taken
} 


\section{Marika Lekakou and Kriszta Szendröi}

(15) Kita tin idrojio. Aftos ine o Vorios Polos ke ekinos ine look-2sG the globe this is the North Pole and that is

o Notios *(Polos).

the South Pole

'Look at the globe. This is the North Pole and that is the South Pole/*one.'

o ekdotikos *(ikos)

the publishing house

'the publishing house'

Moreover, it has been observed (Alexiadou 2001, Campos and Stavrou 2004) that certain ambiguous adjectives only have one reading in polydefinites. Take for example the adjective beautiful in Mary is a beautiful dancer. On the intersective reading of the adjective, Mary is a dancer and she is beautiful, while on the nonintersective reading Mary is beautiful as a dancer. In a polydefinite, the nonintersective is lost, see (17a) (from Campos and Stavrou op.cit.). As expected on our analysis, only the intersective reading is available if the noun is elided, see (17b) (see Branco and Costa 2006 for the same observation in Romance).

a. Gnorises tin orea tin tragudistria?

met-2SG the beautiful the singer

'Did you meet the beautiful singer?' (intersective only)

b. Gnorises tin orea?

met-2SG the beautiful

'Did you meet the beautiful one?' (intersective only)

In general, the adjectives that can receive a restrictive interpretation (and thus appear in polydefinites) are the ones that can partition the noun denotation. This rule out non-intersective adjectives (such as 'former'), since their denotation does not interact with the noun denotation: a former president is not a president. Therefore such adjectives are in principle illicit in polydefinites. However, there is (at least for some speakers) a way to contextually force an intersective interpretation of the adjective, such that an otherwise non-intersective adjective picks out a proper subset of the noun denotation and can thus appear in a polydefinite. For instance, Leu (2007) has pointed out that (18) is possible (for some speakers).

to involve attributive modification inside this nominal DP, since re-ordering of the adjectives, which is otherwise possible in the polydefinite, is impossible, as shown in (ib):

(i)
a. o diasimos o ekdotikos ikos the famous the publishing house
b. *o ekdotikos o diasimos ikos the publishing the famous house 
(18) O PROIGUMENOS o prothipurgos pethane.
the previous the prime minister died
'It is the previous prime minister that died.'

(18) is licit in a context where the speaker corrects another interlocutor (hence the heavy stress on the adjective, notated by capitals), who thought she overheard that the current prime minister died. In this particular context, the noun denotation comprises two disjoint subsets, one containing the current prime minister and the other the previous one. What makes the polydefinite available is that the mention of the current prime minister in the previous discourse discourse-links the set of prime ministers in a salient way, and thus subsequent reference to the previous prime minister satisfies the restrictiveness constraint on polydefinites.

This kind of example is crucial, because it argues against an alternative way of deriving the set of adjectives in polydefinites to the one we have been pursuing here, namely one which invokes a correlation with predicative adjectives. The position held by predicative accounts of polydefinites (Alexiadou and Wilder 1998, Alexiadou 2001, Campos and Stavrou 2004, Panagiotidis 2005, Ioannidou and den Dikken 2006) is that only adjectives that can appear in predicative position are licit in polydefinites. This generalization can derive the facts about relational adjectives, adjectives in proper names and ambiguous adjectives, but Leu's example shows that the proposed correlation breaks down: Proigumenos 'previous' can appear in the polydefinite in the particular context discussed above, but even in this context the adjective is illicit in the post-copular position, as shown in (19). Finally, (20) gives the variant with noun ellipsis, which is, as expected under our analysis, good. ${ }^{5}$

*Aftos o prothipurgos itan PROIGUMENOS.

This the prime minister was previous

O PROIGUMENOS pethane.
The previous died
'The previous one died.'

\section{The 'Extra' Determiner}

In a certain sense, the essence of the polydefinite construction is that it involves multiple instances of the definite determiner. We explain this by assuming that polydefinites are instances of CA, albeit with N-ellipsis. As (6) showed, repeated below as (21), in Greek, multiple instances of the definite article actually appear in CA. So, assimilating the structure of polydefinites to that of CA provides an

\footnotetext{
${ }^{5}$ Among predicative analyses, only the one that assumes an underlying restrictive relative clause (Alexiadou and Wilder 1998) can relate to that the restrictive interpretation of the adjective in polydefinites; a restrictive interpretation is not obligatory in predicative position. For instance, dilitiriodis 'poisonous' can apply to cobras in a subject-predicate copular construction, but as we have seen the corresponding polydefinite is unacceptable.
} 


\section{Marika Lekakou and Kriszta Szendrői}

analysis of the proliferation of determiners: The two (or more) subparts of the CA and the polydefinite are full DPs, headed by their own determiner.

$$
\begin{aligned}
& \text { a. o aetos to puli } \\
& \text { the eagle the bird }
\end{aligned}
$$

b. to puli o aetos
the bird the eagle

It seems to us that our approach fares better than alternative treatments of polydefinites in accounting for the occurrence of multiple determiners. Let us see why.

In the literature, there have essentially been three classes of approaches to polydefinites: Those where predication is involved (e.g. Alexiadou and Wilder 1998, Panagiotidis 2005); those that assume a split DP-structure (e.g. Androutsopoulou 1995, Kariaeva 2004); and those that combine predication and a split-DP structure (e.g. Campos and Stavrou 2004, Ioannidou and den Dikken 2006). These approaches differ in their treatment of the 'extra' definite article.

Alexiadou and Wilder (1998) argue that the underlying structure of Greek polydefinites is a Kayne-style relative clause, as in (22), with, crucially, the subject of the clause a DP, rather than an NP. But this is contrary to Kayne's original proposal and seems ad hoc to us. Presumably, the higher definite article is meant to be responsible for the unique interpretation of the whole DP. But the authors do not clarify what they think the semantic import of the lower definite article, the one on the subject of the relative clause, would be.

$$
\left[\mathrm{DP} \text { the } \mathrm{D}_{\mathrm{D}}[\mathrm{CP}[\mathrm{IP}[\mathrm{DP} \text { the book] [AP red] }]]]\right.
$$

In a different vein, Kariaeva (2004), following earlier work by Androutsopoulou (1995), proposes an analysis of polydefinites in a split-DP framework. She assumes that the Greek DP is split into a DeicticP and a DP with an additional Focus projection inbetween the two, as in (23). She takes AP modifiers to be base-generated at a high (FocP) or low (NumP) functional position within the DP.

\section{[DeicticP [FocP [DP [NumP [NP $]]]]]$}

Kariaeva assumes that if an AP modifier is base generated low, it enters into an agreement relationship with the $\mathrm{N}$ in terms of number and gender, but if it is merged high, i.e. in the FocP above DP, then it has to enter an agreement relation with the DP, and so it will also show definiteness agreement (alongside gender and number agreement). According to Kariaeva, this gives rise to a phonological copy of the definite article on the modifying adjective. However, no independent argumentation is offered to support the assumption that high merger of the adjectival modifier triggers definiteness agreement on the adjective.

Other approaches to polydefinites take one of the determiners to be a spell-out of $\mathrm{D}$, and the other(s) to be the phonological instantiation of some functional head in the extended nominal projection (Pred in Campos and Stavrou 2004; Deixis and Focus in Ioannidou and den Dikken 2006). In our view, neither of these 


\section{Multiple Determiners in Greek}

approaches are forthcoming in their explanation as to why the relevant functional heads would be systematically homophonous to the definite article. In addition, as pointed out to us by Hedde Zeijlstra (p.c.), such approaches also face the potential problem of having to provide appropriate semantic meaning to the proposed functional heads. Otherwise, the labels become vacuous.

So, in our view, no existing alternative approach actually derives the presence of extra determiner(s) in a polydefinite, although this follows straightforwardly on our own approach. ${ }^{6}$ However, even though we can capture the occurrence of multiple determiners in the morpho-syntax, we need to say something in addition regarding the semantics.

When faced with the multiple occurrence in the syntax of something which is only interpreted once in the semantics, in principle there are (at least) two options available: One is to take one of the occurrences as the semantically real one, and treat the rest as 'expletive' (or as realizations of different syntactic entities, as in some of the aforementioned proposals). The other option, a more radical one, is to say that all overt instances are actually 'expletive', and locate the source of the semantic effect in a phonologically non-realized element. The latter approach has an immediate advantage over the former one: It does not entail massive lexical ambiguity. What looks like the definite determiner is always the same element, but it is actually not the element responsible for the semantic effect.

This line of reasoning, which is the one we will follow in this paper, has been pursued for negative concord by Zeijlstra (2004). For strict negative concord languages, like Greek, Zeijlstra argues that (what looks like) the marker of sentential negation is actually not interpreted as negative. Rather, semantic negation is contributed by a covert negative operator, and the overtly realized 'negative' elements (sentential negation and negative polarity items) are semantically non-negative (they bear uninterpretable Neg features checked against the interpretable Neg feature of the covert negative operator).

That a similar situation obtains in the realm of definiteness in Greek is evident from polydefinites. A polydefinite, such as to megalo to spiti 'out of the houses the big one' refers to a unique big house. But the definite articles on 'house' and on 'big' are not interpreted: In a discourse context where to megalo to spiti is felicitously used, there cannot be a unique house (otherwise the restrictive interpretation of the adjective would be impossible) and there is no commitment carried by the definite on the adjective that there is a unique big entity. So, it seems that semantically, both definite articles are vacuous at the position where

\footnotetext{
${ }^{6}$ Panagiotidis (2005) also proposes that polydefinites involve two DPs, of which the adjectival one contains noun ellipsis. As a result, he too can account for the presence of the extra determiner. One important difference, however, is that on his proposal one DP is the subject and the other the predicate in a small clause structure. Thus, under his analysis, one of the DPs, and not necessarily the adjectival one, is a predicate. But this claim is not sufficiently motivated. Moreover, to the extent that the proposal aims to explain the restrictions on the set of admissible adjectives on the basis of the adjectival DP being predicative, it gives the incorrect prediction that these restrictions only apply in the DNDA order, as it is only in this order that the adjectival DP is the predicate.
} 


\section{Marika Lekakou and Kriszta Szendrői}

they surface. Definiteness is interpreted on the large DP as a whole, i.e. it applies at the intersection of sets of big entities and sets of houses. This ties in with the issue, already mentioned in Section 1.2, that the DP subparts of a polydefinite have to be allowed to be of type $<e, t>$, so that their semantic composition can involve set intersection.

Adopting Zeiljstra's view of strict negative concord for the encoding of definiteness in Greek, we propose the following. The Greek definite article, D, is semantically empty. The semantics of definiteness (and referentiality) associated with it is encoded above D, usually in the form of an empty operator (though see below). Thus, overt definite Ds does not in themselves carry a uniqueness presupposition and do not saturate the nominal predicate; what does that is the empty operator projected above D. In the case of a monadic definite, one D-head and one operator are merged, giving rise to the expected syntax and semantics. In a polydefinite, two DP's are merged, but only one empty operator is projected above the composite DP, giving rise to a unique saturated nominal. We can exclude the possibility of merging multiple nominal projections that have a $\mathrm{D}$ and a covert operator each, because there would be no semantic composition rule to combine two saturated nominals (other than coordination, of course).

We would like to speculate that the proposed split nature of the definite article in Greek is evident in other cases in the language. For instance, demonstratives and proper names are often treated as definites. Contrary to English, the Greek definite article obligatorily co-occurs with both these, suggesting that it is not itself the locus of definiteness:

$$
\begin{array}{ll}
\text { afto to vivlio } & * \text { this the book } \\
\text { o Jannis } & * \text { the John }
\end{array}
$$

A comprehensive treatment of the encoding of definiteness in Greek awaits future research.

\section{References}

Alexiadou, Artemis. 2001. Adjective syntax and noun raising: Word order asymmetries in the DP as the result of adjective distribution. Studia Linguistica 55:217-248.

Alexiadou, Artemis, and Chris Wilder. 1998. Adjectival modification and multiple determiners. In A. Alexiadou, and C. Wilder, eds., Possessors, predicates and movement in the DP, 303-332. Amsterdam: John Benjamins.

Androutsopoulou, Antonia. 1995. The licensing of adjectival modification. In Jose Camacho, Lina Choueiri, and Maki Watanabe, eds., Proceedings of the $14^{\text {th }}$ West Coast Conference on Formal Linguistics, 17-31. Stanford: CSLI.

Baker, Mark, and O.T. Stewart. 1999. On double-headedness and the anatomy of the clause. Ms., Rutgers University. 


\section{Multiple Determiners in Greek}

Branco, Antonio, and Francisco Costa. 2006. Noun ellipsis without empty categories. In S. Müller, ed., Proceedings of the $13^{\text {th }}$ International Conference on Head-Driven Phrase Structure Grammar, 81-101. Stanford: CSLI.

Campos, Hector, and Melita Stavrou. 2004. Polydefinites in Greek and Aromanian. In O. Tomic, ed., Balkan syntax and semantics, 137-173. Amsterdam: John Benjamins.

Giannakidou, Anastasia, and Melita Stavrou. 1999. Nominalization and ellipsis in the Greek DP. The Linguistic Review 16:295-331.

Heim, Irene, and Angelika Kratzer. 1998. Semantics in generative grammar. Oxford: Blackwell.

Higginbotham, James. 1985. On semantics. Linguistic Inquiry 16:547-593.

Huddleston, Rodney, and Geoffrey Pullum 2002. The Cambridge grammar of the English language. Cambridge: Cambridge University Press.

Ioannidou, Alexia, and Marcel den Dikken. 2006. P-drop, D-drop, D-spread. Ms., City University of New York Graduate Center.

Kariaeva, Natalia. 2004. Determiner spreading in Modern Greek: Split-DP hypothesis. Ms., Rutgers University.

Kolliakou, Dimitra. 2004. Monadic definites and polydefinites: Their form, meaning and use. Journal of Linguistics 40:263-333.

Lekakou, Marika, and Kriszta Szendröi. 2007. Eliding the noun in close apposition, or Greek polydefinites revisited. University College London Working Papers in Linguistics 19:129-154. London: Department of Phonetics and Linguistics, University College London.

Lekakou, Marika, and Kriszta Szendröi. 2009. Close apposition with and without noun ellipsis: An analysis of Greek polydefinites. In press in Studies in Greek Linguistics 29: Proceedings of the Annual meeting of the Department of Linguistics, School of Philology, Faculty of Philosophy, Aristotle University of Thessaloniki, 10-11 May 2008, 151-166. Thessaloniki: Institute of Modern Greek Studies.

Leu, Tom. 2007. From Greek to Germanic: Poly(*in)definiteness and weak/strong adjectival inflection. Ms., New York University.

Panagiotidis, Phoevos. 2005. Determiner spreading as DP-predication. Ms., Cyprus College.

Potts, Chris. 2005. The logic of conventional implicature. Oxford: Oxford University Press.

Ralli, Angela, and Melita Stavrou. 1998. Morphology-syntax interface: A-N compounds vs. A-N constructs in Modern Greek. In Geert Booij and Jaap van Marle, eds., Yearbook of Morphology 1997, 243-264. Dordrecht: Kluwer.

Stavrou, Melita. 1995. Epexegesis vs. apposition. Scientific Yearbook of the Classics Department. Aristotle University of Thessaloniki.

Stavrou, Melita. 2009. Postnominal adjectives in Greek indefinite noun phrases. To appear In L. Brugè, A. Cardinaletti, G. Giusti, N. Munaro, C. Poletto, eds., Functional heads. Papers in honour of Guglielmo Cinque for his $60^{\text {th }}$ anniversary. Oxford: Oxford University Press. 


\section{Marika Lekakou and Kriszta Szendrői}

Williams, Edwin. 1981. Argument structure and morphology. The Linguistic Review 1:81-114.

Williams, Edwin. 1989. The anaphoric nature of theta-roles. Linguistic Inquiry 20:425-256.

Williams, Edwin. 1997. Blocking and anaphora. Linguistic Inquiry 28:577-628.

Zeijlstra, H. 2004. Sentential negation and negative concord. Ph.D. diss., University of Amsterdam.

Marika Lekakou

Meertens Institute

Joan Muyskenweg 25

1096 CJ Amsterdam

The Netherlands

marika.lekakou@meertens.knaw.nl

Kriszta Szendröi

UCL Linguistics

Gower Street

London WC1E 6BT

United Kingdom

k.szendroi@ucl.ac.uk 